\title{
Correlation between body mass index and prostate volume in benign prostatic hyperplasia patients undergoing holmium enucleation of the prostate surgery
}

Ken Batai ${ }^{1}$, Michael Phung ${ }^{2}$, Robert Bell ${ }^{3}$, Aye Lwin ${ }^{1}$, Kieran A. Hynes ${ }^{4}$, Elinora Price ${ }^{5}$, Karleen M. Meiklejohn ${ }^{6}$, Erika R. Bracamonte ${ }^{6}$ and Joel T. Funk ${ }^{1 *}$

\begin{abstract}
Background: Benign prostatic obstruction (BPO) due to benign prostatic hyperplasia (BPH) is a leading cause of morbidity in men over the age of 40. This study examined whether there was an association between body mass index (BMI) and pre-operative prostate volume and whether expression of two genes, alpha-2-macroglobulin (A2M) and transforming growth factor beta 3 (TGFB3), was correlated with BMI, pre-operative prostate volume, and age at surgery.
\end{abstract}

Methods: Medical records of patients who underwent holmium enucleation of the prostate surgery for treatment of BPO were retrospectively reviewed. Surgical specimens were obtained from formalin-fixed paraffin-embedded blocks, and expression of the targeted genes was quantified using a real time PCR approach. Linear regression analysis was performed to assess association between BMI and prostate volume adjusting for demographic characteristics and comorbidity. Spearman's correlation was used to examine whether gene expression was correlated with BMI, prostate volume, and age at surgery.

Results: A total of 278 patients were identified, including 62.9\% European Americans ( $\mathrm{n}=175)$ and $27.7 \%$ Hispanic Americans $(n=77)$. BMI was significantly correlated with prostate volume (Spearman's $r h o=0.123, P=0.045)$. In linear regression analysis, $\mathrm{BMI}$ was positively associated with prostate volume $(\beta=0.01, P=0.004)$, while hyperlipidemia was negatively associated with prostate volume $(\beta=-0.08, P=0.02)$. A trend for a positive association was also observed for diabetes $(\beta=0.07, P=0.099)$. In the race/ethnicity stratified analysis, age at surgery showed a trend for significantly positive association with prostate volume in European Americans $(\beta=0.005, P=0.08)$, but not in Hispanic Americans. Expression of the $A 2 M$ gene in the stroma was negatively correlated with age at surgery $(P=0.006)$. $A 2 M$ expression in the gland was positively correlated with prostate volume among older men (Age $\geq 70, P=0.01)$ and overweight men (BMI 25-30, $P=0.04$ ). TGFB3 expression in the gland was positively correlated with BMI $(P=0.007)$ among older men.

Conclusions: This study demonstrated the positive correlation between BMI and prostate volume. Expression of TGFB3 and A2M was correlated with BMI, prostate volume, and age at surgery.

Keywords: Obesity, Co-morbidity, Health disparities

\footnotetext{
*Correspondence: jfunk@surgery.arizona.edu

${ }^{1}$ Department of Urology, The University of Arizona, 1501 N Campbell Ave,

PO Box 245077, Tucson, AZ 85724-5077, USA

Full list of author information is available at the end of the article
}

(c) The Author(s) 2021. Open Access This article is licensed under a Creative Commons Attribution 4.0 International License, which permits use, sharing, adaptation, distribution and reproduction in any medium or format, as long as you give appropriate credit to the original author(s) and the source, provide a link to the Creative Commons licence, and indicate if changes were made. The images or other third party material in this article are included in the article's Creative Commons licence, unless indicated otherwise in a credit line to the material. If material is not included in the article's Creative Commons licence and your intended use is not permitted by statutory regulation or exceeds the permitted use, you will need to obtain permission directly from the copyright holder. To view a copy of this licence, visit http://creativecommons.org/licenses/by/4.0/. The Creative Commons Public Domain Dedication waiver (http://creativeco mmons.org/publicdomain/zero/1.0/) applies to the data made available in this article, unless otherwise stated in a credit line to the data. 


\section{Background}

Benign prostatic obstruction (BPO) due to benign prostatic hypertrophy $(\mathrm{BPH})$, enlargement of the prostate gland, is a leading cause of morbidity in men over the age of 40. The prevalence of $\mathrm{BPO} / \mathrm{BPH}$ increases with advancing age reaching $100 \%$ in the ninth decade of life [1]. At present, patients with $\mathrm{BPO} / \mathrm{BPH}$ are treated with medical therapy consisting of alpha-adrenergic antagonists, 5-alpha-reductase inhibitors or surgery. Medical therapy can lead to considerable side effects including hypotension, erectile dysfunction, gynecomastia, and retrograde ejaculation. Furthermore, surgical treatment can lead to complications such as urinary incontinence, bleeding, urethral stricture disease, or bladder neck contracture [1].

The current guidelines for the management of $\mathrm{BPH}$ recommend to treat initially with medical therapy until the disease process progresses to a point at which surgery is a necessity [2]. Unfortunately, $\mathrm{BPO} / \mathrm{BPH}$ progression is not fully studies $[3,4]$, and there is a shortage of literature to guide the decisions surrounding when to intervene with definitive surgical therapy in order to avoid adverse outcomes as well as a limited understanding of which patients progress in their disease and why.

Although current BPH and lower urinary tract symptoms (LUTS) studies rarely report racial/ethnic prevalence, it has been reported that men from minority groups, such as Hispanic-Americans (HAs) and African Americans, are at higher risk of developing $\mathrm{BPH}$ [5-9]. Additionally, there have been multiple studies reporting the effects of obesity and metabolic syndrome (hypertension, high blood sugar, obesity, waist circumference, and hyperlipidemia) on BPH. Although there is no clear consensus yet, obesity, higher body mass index (BMI), and metabolic diseases were associated risk factors of $\mathrm{BPH}$ [7, 9-17]. Despite high prevalence of obesity in HAs and African Americans [18, 19], the relationship between obesity and BPH in these groups and cause for disparities are not fully explored.

It has been hypothesized that pro-inflammatory states due to obesity may be triggers for developing $\mathrm{BPH}$ and there may be reactive changes characterized by alterations in the stromal and epithelial microenvironment, reflected in changes in expression of genes involved in inflammatory response and cell growth and development $[12,20]$. However, it is still unclear how obesity and metabolic diseases affect BPH pathologic and molecular profiles, especially in medically underserved populations like HAs.

Two main goals of this study were 1) to examine whether there was an association between higher BMI or obesity and prostate volume including HAs who are previously underrepresented in $\mathrm{BPH}$ research and 2) to investigate whether expression of three genes, Insulin like growth factor 2 (IGF2), alpha-2-macroglobulin (A2M), and transforming growth factor beta 3 (TGFB3), was correlated with BMI, pre-operative prostate volume, and age at surgery. We also assessed if age and self-identified race/ethnicity modified these relationships.

\section{Methods \\ BPH patients}

Electronic medical record of consecutive patients who underwent (HoLEP) surgery for treatment of $\mathrm{BPO} / \mathrm{BPH}$ between October 2012 and June 2018 were retrospectively reviewed. Patients who had histologically confirmed BPH were included. Patients with (a) pathology diagnoses other than $\mathrm{BPH},(\mathrm{b})$ a history of prostate cancer, or (c) a prior surgical intervention for $\mathrm{BPO} / \mathrm{BPH}$ were not included. Chart review was conducted on every eligible patient in the identified timeframe. Clinical (e.g., histology, pre-operative prostate volume, and medication) and demographic (e.g., age and race/ethnicity) characteristics as well as BMI, smoking status, and comorbidities (e.g., diabetes, hypertension, and hypolipidemia) were extracted. The pre-operative prostate volume was estimated using the ellipsoid formula (length $\mathrm{x}$ width $\mathrm{x}$ height $\mathrm{x}(\pi / 6)$ based on either transrectal ultrasound or cross-sectional imaging (MRI or CT). The study protocol was approved by the University of Arizona Institutional Review Board.

\section{Prostate tissue samples}

To prepare the surgical specimens for gene expression analysis, hematoxylin and eosin (H\&E) slides associated with formalin-fixed paraffin-embedded (FFPE) tissue samples underwent a review by board certified genitourinary pathologists to identify different architectural and cellular components (the stromal-rich and glandular/ epithelium-rich areas) on the slides. Then, from the FFPE tissue sample, $1.5 \mathrm{~mm}^{2}$ punches from each identified area (the stromal-rich or the glandular/epithelium-rich area) were taken.

\section{RNA extraction and gene expression analysis}

The Roche high Pure FFPET kit was used to extract RNA, and RNA was quantified using Nanodrop. Three genes, $I G F 2, A 2 M$, and TGFB3, were selected from Luo et al. [21]. Two genes, $A 2 M$ and TGFB3, were successfully amplified, but due to technical issues IGF2 was not successfully amplified. The samples from 30 patients yielded quantifiable RNA expression data using a real time PCR approach. $\triangle \mathrm{Ct}$ method and a housekeeping gene, 18SrRNA, were used for normalization. $\Delta$ Ct was $\log 2$ transformed for statistical analysis. 


\section{Statistical analysis}

Chi-square test, independent sample T-test, and MannWhitney U-test were performed to characterize eligible patients for this study and patients included for the gene expression study. Linear regression analysis was performed to test the association between BMI and preoperative prostate volume. Pre-operative prostate volume was log-transformed to normalize. Backward selection approach was used to determine variables to include in the regression mode. Age and race/ethnicity were added to the model to assess if they altered the association between BMI and prostate size. Spearman's correlation was used to examine whether gene expression was correlated with BMI, prostate volume, and age at surgery. Separate analysis was performed for younger men (age $<70)$ and older men (age $\geq 70$ ) as well as European Americans (EAs) and HAs to assess if associations were different in these groups.

\section{Results}

A total of 278 patients who met inclusion criteria were identified. The mean age of patients was 70.6 (SD 8.5). The largest group of patients was EAs (62.9\%), and HAs were the second largest group of patients (27.7\%). BMI was significantly correlated with pre-operative prostate volume (Spearman's $r h o=0.123, P=0.045$, Fig. 1). Similar correlations were observed when stratified analysis was performed based on age and race/ethnicity (Additional file 1: Supplementary Table 1). Age at surgery was not correlated with prostate volume but was correlated with BMI (Spearman's rho $=-0.169, P=0.005$ ). The correlation was stronger in EAs than in HAs. Median pre-operative prostate volume was $75 \mathrm{~mL}$ (Interquartile Range, 48.8-105.0). Characteristics of patients with smaller prostate volume $(\leq 75 \mathrm{~mL})$ and larger prostate (>75 mL) were compared (Table 1). Patients with larger prostates had significantly higher BMI compared to patients with smaller prostate volume $(P=0.03)$. Urinary retention was more common in men with larger prostate (44.7\% and $55.9 \%$ in men with small and larger prostate respectively, $P=0.04$ ).

The linear regression analysis was performed to assess if BMI was associated with pre-operative prostate volume (Table 2). BMI, hyperlipidemia, and diabetes remained in the model using the backward selection approach. BMI was positively associated with pre-operative prostate volume $(\beta=0.01, P=0.004)$. Hyperlipidemia was negatively associated with prostate volume $(\beta=-0.08, P=0.02)$, and a trend for a positive association was observed for diabetes $(\beta=0.07, P=0.099)$. Additionally, including age at surgery and race/ethnicity in the model did not change the association between BMI and prostate volume. In the race/ethnicity stratified analysis, the association between BMI and prostate volume was similar in both groups, but association was no longer significant in HAs, possibly due to small sample size (Additional file 1: Supplementary Table 2). Interestingly, age at surgery showed a trend for significantly positive association with prostate volume in EAs $(\beta=0.005, P=0.08)$, but not in HAs. The analysis

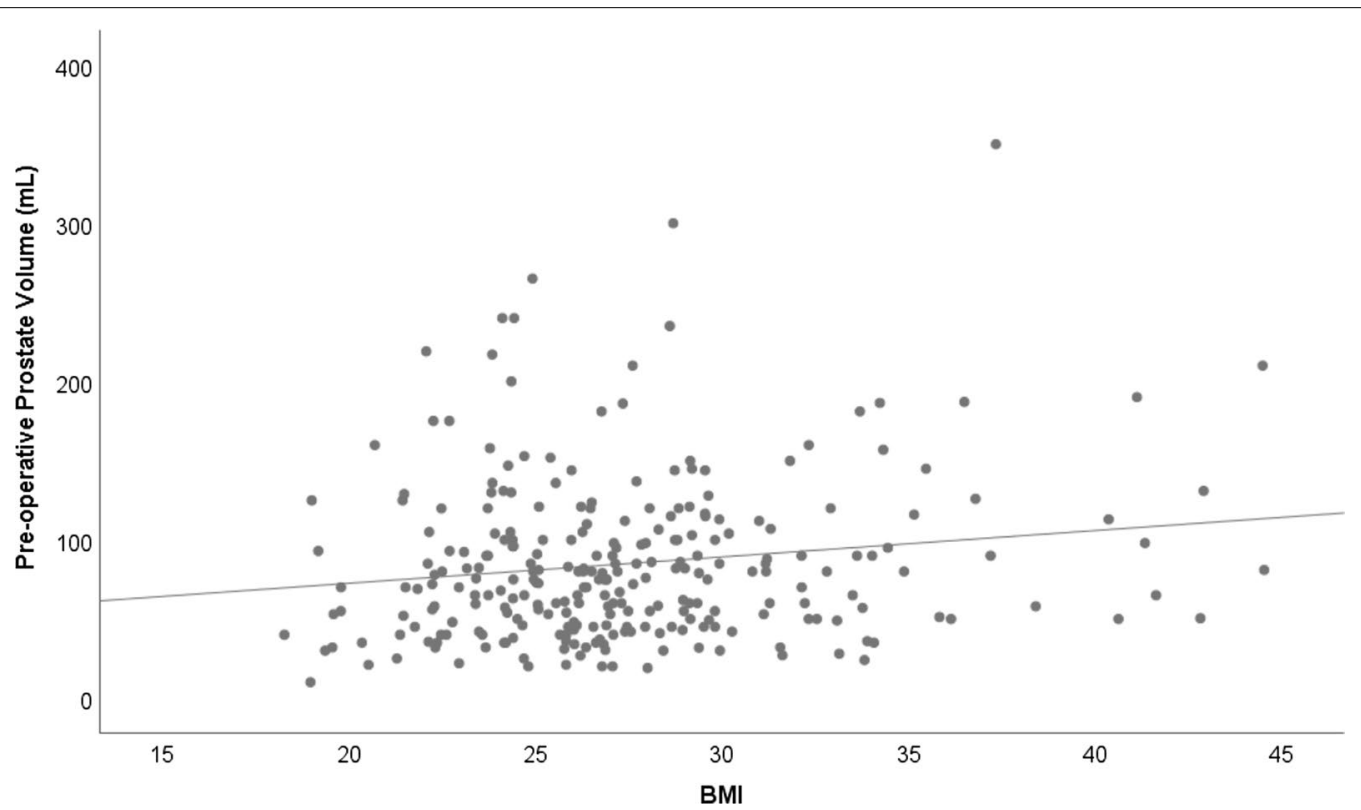

Fig. 1 Correlation between pre-operative prostate volume $(\mathrm{mL})$ and BMI (Spearman's rho $=0.123, p=0.045$ ) 
Table 1 BPH patients characteristics stratified by pre-operative prostate volume

\begin{tabular}{|c|c|c|c|}
\hline & Prostate volume $\leq 75 \mathrm{~mL}$ & Prostate volume $>75 \mathrm{~mL}$ & $P$ \\
\hline Age, mean (SD) & $70.8(8.8)$ & $70.5(8.2)$ & 0.81 \\
\hline Race/ethnicity, n (\%) & & & 0.48 \\
\hline European Americans & $91(64.5)$ & $84(61.3)$ & \\
\hline Hispanic/latino & $35(24.8)$ & $42(30.7)$ & \\
\hline Other/unknown & $15(10.6)$ & $11(8.0)$ & \\
\hline BMI, median (IQR) & $26.3(24.1-29.0)$ & $27.2(24.2-29.9)$ & 0.03 \\
\hline Smoking history, n (\%) & & & 0.30 \\
\hline Never & $79(60.8)$ & $73(57.5)$ & \\
\hline Former smoker & $40(30.8)$ & $48(37.8)$ & \\
\hline Currently smoker & $11(8.5)$ & $6(4.7)$ & \\
\hline Urinary tract Infection, n (\%) & & & 0.39 \\
\hline No & $113(80.1)$ & $111(82.2)$ & \\
\hline Yes & $28(19.9)$ & $24(17.8)$ & \\
\hline Urinary retention, n (\%) & & & 0.04 \\
\hline No & $78(55.3)$ & $60(44.1)$ & \\
\hline Yes & $63(44.7)$ & $76(55.9)$ & \\
\hline Bladder stone, n (\%) & & & 0.19 \\
\hline No & $128(90.8)$ & $117(86.7)$ & \\
\hline Yes & $13(9.2)$ & $18(13.3)$ & \\
\hline Diabetes, n (\%) & & & 0.23 \\
\hline No & $114(80.9)$ & $104(76.5)$ & \\
\hline Yes & $27(19.1)$ & $32(23.5)$ & \\
\hline Hyperlipidemia, n (\%) & & & 0.21 \\
\hline No & $80(56.7)$ & $84(62.2)$ & \\
\hline Yes & $61(43.3)$ & $51(37.8)$ & \\
\hline Hypertension, n (\%) & & & 0.30 \\
\hline No & $65(46.1)$ & $57(42.2)$ & \\
\hline Yes & $76(53.9)$ & $78(57.8)$ & \\
\hline
\end{tabular}

Note: $P<0.05$ using Independent sample T-test for age and Chi-square tests for other variables. Bold values indicate statistically significant $(P<0.05)$

$B M I$ body mass index, $B P H$ benign prostatic hyperplasia, IQR interquartile range, $S D$ standard deviation

stratified based on age revealed similar association in younger and older men.

We then assessed the correlation of gene expression with age at surgery, BMI, and pre-operative prostate volume (Table 3). The characteristics of patients selected for gene expression analysis are presented on Additional file 1: Supplementary Table 3. Expression of the $A 2 M$ gene in the stroma was significantly negatively correlated with age at surgery $(P=0.006)$. In the stratified analysis, the correlation was significant in HAs, men with normal BMI $(\mathrm{BMI}<25)$, and obese men $(\mathrm{BMI}>30)$ (Additional file 1: Supplementary Table 4). $A 2 M$ expression in the gland was significantly positively correlated with prostate volume among older men (Age $\geq 70, P=0.01$ ) and overweight men (BMI 25-30, $P=0.04$ ). Among older men, TGFB3 expression in the gland was significantly positively correlated with BMI (Spearman's $r h o=0.709$,
$P=0.007)$ and showed a trend for significant correlation with prostate volume $(P=0.08)$.

\section{Discussion}

In this study, we demonstrated the positive correlation between BMI and pre-operative prostate volume. We also demonstrated gene expression of TGFB3 and $A 2 M$ and its associations with BMI, preoperative prostate volume, and age at surgery. We also investigated if age and race/ethnicity modified the patterns of correlations.

Although multiple studies have examined the relationships between obesity, particularly abdominal obesity, and BPH risk [7, 12], there are fewer studies that incorporate pre-operative prostate volume, especially in racial/ethnic groups that are affected by both obesity and $\mathrm{BPH}$. Our findings confirmed findings from previous studies and demonstrated a correlation between BMI 
Table 2 Linear regression showing association between body mass index and pre-operative prostate volume

\begin{tabular}{|c|c|c|c|c|c|c|}
\hline & \multicolumn{2}{|c|}{ Unadjusted } & \multicolumn{2}{|c|}{ Adjusted model 1} & \multirow{2}{*}{$\frac{\text { Adjusted model } 2}{\beta}$} & \multirow[t]{2}{*}{$P$} \\
\hline & $\beta$ & $P$ & $\beta$ & $P$ & & \\
\hline Age at surgery & 0.002 & 0.19 & & & 0.003 & 0.13 \\
\hline $\mathrm{BMl}$ & 0.009 & 0.006 & 0.010 & 0.004 & 0.010 & 0.002 \\
\hline \multicolumn{7}{|l|}{ Race/ethnicity } \\
\hline HAs versus EAs & 0.031 & 0.38 & & & 0.030 & 0.39 \\
\hline $\begin{array}{l}\text { Others versus } \\
\text { EAs }\end{array}$ & -0.043 & 0.42 & & & -0.054 & 0.16 \\
\hline \multicolumn{7}{|l|}{ Smoking } \\
\hline $\begin{array}{l}\text { Non-smokers } \\
\text { versus former } \\
\text { smokers }\end{array}$ & 0.034 & 0.32 & & & & \\
\hline $\begin{array}{l}\text { Non-smokers } \\
\text { versus current } \\
\text { smoker }\end{array}$ & -0.141 & 0.03 & & & & \\
\hline Diabetes & 0.051 & 0.17 & 0.066 & 0.099 & 0.054 & 0.16 \\
\hline Hyperlipidemia & -0.047 & 0.13 & -0.080 & 0.02 & -0.074 & 0.02 \\
\hline Hypertension & 0.001 & 0.98 & & & & \\
\hline UTI & 0.008 & 0.84 & & & & \\
\hline Bladder stone & 0.051 & 0.29 & & & & \\
\hline
\end{tabular}

Note Adjusted model 1 is based on backward selection, and BMI, diabetes, and hyperlipidemia were retained in the final mode. Additionally adjusted for age at surgery and race/ethnicity in model 2 . Bold values indicate statistically significant $(P<0.05)$

$B M I$ body mass index, EA European Americans, HA Hispanic Americans, UTI urinary tract infection

Table 3 Correlation between clinical/demographic variables and gene expression (Spearman's correlation coefficient and $P$-value)

\begin{tabular}{cccc}
\hline & Age at surgery & BMI & $\begin{array}{l}\text { Pre-operative } \\
\text { prostate volume }\end{array}$ \\
\hline All $(\mathrm{n}=30)$ & & & \\
A2M & & & \\
Gland & $-0.068(0.72)$ & $0.222(0.16)$ & $0.277(0.14)$ \\
Stroma & $-\mathbf{0 . 4 9 8 ( 0 . 0 0 6 )}$ & $0.221(0.27)$ & $-0.098(0.61)$ \\
TGFB3 & & & \\
Gland & $0.000(1.00)$ & $0.207(0.30)$ & $0.326(0.08)$ \\
Stroma & $-0.298(0.17)$ & $0.321(0.16)$ & $0.065(0.77)$ \\
\hline
\end{tabular}

Note: Bold values indicates statistically significant $(P<0.05)$

$B M I$ body mass index

and prostate volume [9-11, 15-17, 20]. Fowke and colleagues showed that prostate volume was significantly positively associated with BMI, waist-hip ratio, waist circumference, percent body fat, total fat mass, and total lean mass [20]. Kim et al. demonstrated positive correlations between BMI and prostate volume and between BMI and International Prostate Symptom Score among Korean men [11]. A study from Japan even developed a validated model to estimate prostate volume $(>40 \mathrm{~mL})$ based on age, PSA, percent free PSA, and body weight
[22]. Despite these studies, there are reports that demonstrate no correlation between BMI or body weight and $\mathrm{BPH}[23,24]$. Contrary to our finding, Yee et al. investigated the relationship between obesity and LUTS, and they found that men with higher BMI had a smaller prostate than men with lower BMI at baseline [25]. Moreover, weight loss did not improve LUTS after intervention.

Previous studies also demonstrated that Hispanic ethnicity was associated with $\mathrm{BPH}$ risk with increased rates of reporting LUTS $[7,8]$. Obesity is more prevalent among HAs than EAs [26, 27]. The 2014 National Health Interview Survey analysis results also show that HAs have a higher prevalence of diabetes than EAs [28]. Moreover, the prevalence of diabetes is slightly higher in Mexican Americans, especially Mexican American men, than HAs of other origins [26]. We hypothesized that men from minority groups, such as HAs, who were obese and had metabolic diseases were disproportionately affected by BPH. When stratifying by race/ethnicity, both EA and HA had a positive correlation between BMI and preoperative prostate volume, but correlation was significant only for EAs, probably due to small sample size for HAs.

Contrary to our hypothesis, hyperlipidemia was negatively associated with pre-operative prostate volume, and we did not observe significant association for diabetes or hypertension. There have been multiple studies 
interested in demonstrating the link between metabolic syndrome and $\mathrm{BPH}$, but findings have been inconsistent. Some studies have reported how diabetes [13, 14] and hyperlipidemia $[13,29]$ were correlated with $\mathrm{BPH}$, while other studies have failed to demonstrate an association $[23,24]$. Egan and colleagues investigated the correlation between metabolic diseases and BPH in National Health and Nutrition Examination Surveys [24]. They found that cardiovascular disease, diabetes, or hypertension were not associated with BPH after adjusting for social and behavioral factors. When breaking down the components of metabolic syndrome or looking at metabolic syndrome as a whole, Telli et al. found no evidence to support any association between metabolic syndrome and LUTS [23]. The clinical significance of current and previous studies is uncertain, because of the consistent, but weak association between obesity and prostate volume, and inconsistent associations between metabolic diseases and BPH. Since obesity rates continue to increase in racial/ethnic minority groups, impact of obesity on $\mathrm{BPH}$ and its clinical implications need further investigation. The obesitydriven $\mathrm{BPH}$ may have a different pathophysiological basis from the hormonally-driven or age related progression of $\mathrm{BPH}$, and understanding of pathophysiological basis of obesity-driven may open up a new avenue for treatment.

To explore the biological basis of obesity-driven $\mathrm{BPH}$, we examined the correlations between obesity and expression of genes that are potentially related to obesity. We demonstrated how expression of two genes, $A 2 M$ and TGFB3, were correlated with age at surgery, $\mathrm{BMI}$, or preoperative prostate volume. These two genes along with IGF2 were selected as genes of interest in $\mathrm{BPH}$ because they were over-expressed in $\mathrm{BPH}$ compared to normal prostate tissue in a previous study by Luo et al. [21] and these gene may play roles in obesity [30-33]. A2M was also over-expressed in BPH compared to normal prostate tissue in another study [34]. TGFB3 and IGF2 are both growth factors, and TGFB3 encodes a ligand of the transforming growth factor-beta (TGFbeta) superfamily. $A 2 M$ encodes a protease inhibitor and cytokine transporter, and the protein encoded by $A 2 M$ can inhibit inflammatory cytokines and interrupt inflammatory cascades. A more recent molecular profiling study using RNA sequencing further demonstrated that $A 2 M$ and TGFB3 were over-expressed in $\mathrm{BPH}$ [35]. However, this study identified BMP5 and CXCL13 as the two most significantly over-expressed genes in $\mathrm{BPH}$. BMP5 (bone morphogenetic protein 5) also encodes a ligand of the TGF-beta superfamily. Ligands of this protein family bind TGF-beta receptors and activate SMAD family transcription factors. Dysregulation of TGFB3 and $B M P 5$ may affect expression of downstream genes that are involved in $\mathrm{BPH}$ progression. CXCL13 (C-X-C motif chemokine ligand 13) is an antimicrobial peptide and CXC chemokine, a small cytokine. Both growth factors and immune response are likely to be involved in epithelial and stromal growth in the prostate promoting development and progression of BPH [4, 36-38], but growth factors and inflammatory response gene may not influence prostate volume uniformly in all racial/ethnic and age groups. Moreover, a molecular profiling study identified two distinct subtypes of BPH, subtype A enriched with stromal signatures and subtype B associated with obesity and hypertension [39]. This current study also observed different gene expression correlation patterns for different cell types, race/ethnicity, and age groups. The difference in gene expression patterns between cell types or between patients' demographic backgrounds and co-morbid conditions needs to be further investigated with a larger sample.

The limitations of this study include its retrospective nature and small sample size at a single institution. Only 278 patients met our inclusion criteria, but we provide surgical care for a diverse patient population due to our location in the Southwestern United States. To our knowledge, this is the first study to explore the relationship between obesity and BPH in HA men in the United States. Secondly, the prostate volume was measured using ultrasound, CT, or MR. Different measurement methods may create systematic bias causing false positive or negative associations. Moreover, we explored the correlation between expression of only three genes and $\mathrm{BPH}$ characteristics in a small subset of patients, and we failed to amplify one of the genes, IGF2. All the patients included were had advanced BPH that required a surgical treatment and they were receiving medical management with alpha blockade and/or 5-alpha reductase inhibitors. Medications may have altered the correction between BMI and prostate volumes or between metabolic diseases and prostate volumes. Inclusion of patients with less severe $\mathrm{BPH}$ or $\mathrm{BPO}$ who have not undergone surgical or therapeutic treatment and a multi-institutional study with a larger sample size and a more diverse patient population is warranted to further investigate the impact of obesity or obesity related diseases on $\mathrm{BPH}$ and $\mathrm{BPO}$ characteristics. Finally, there is a paucity of data regarding molecular risk factors in patients with $\mathrm{BPH}$. Further studies are needed to identify genes linked to $\mathrm{BPH}$, so precision medicine can be used to predict disease progression, treatment response, and clinical outcomes.

\section{Conclusions}

We demonstrated the positive association between BMI and pre-operative prostate volume. We also demonstrated the association between gene expression of TGFB3 and $A 2 M$ with BMI, preoperative prostate 
volume and age at surgery. Further studies are needed to confirm these findings.

\section{Abbreviations}

BMI: Body mass index; BPH: Benign prostatic hyperplasia; BPO: Benign prostatic obstruction; CT: Computed tomography; EA: European Americans; FFPE: Formalin-fixed paraffin-embedded; HA: Hispanic Americans; HoLEP: Holmium enucleation of the prostate; LUTS: Lower urinary tract symptoms; MRI: Magnetic resonance imaging; PCR: Polymerase chain reaction; RNA: Ribonucleic acid; SD: Standard deviation.
\end{abstract}

\section{Supplementary information}

Supplementary information accompanies this paper at https://doi.org/10. 1186/s12894-020-00753-9.

Additional file 1. Suppmentary Tables.

\section{Acknowledgements}

The authors would like to thank everyone who helped prepare clinical data from Banner University Medical Center, particularly Myra Ortega.

\section{Authors' contributions}

Study design: KB, MP, ERB, JTF; acquisition of data: KB, MP, RB, AL, KAH, EP, KMM; statistical analysis: KB; Interpretation of data: KB, MP, RB, JTF; manuscript preparation: KB, MP, RB, AL, JTF; project supervision: ERB, JTF. All authors read and approved the final manuscript.

\section{Funding}

This research project was funded by a grant from the Arizona Area Health Education Centers (AHEC) Program. The content is solely the responsibility of the authors and does not necessarily represent official views of Arizona AHEC.

\section{Availability of data and materials}

All the data are available upon request.

\section{Ethics approval and consent to participate}

Retrospective study of clinical chart review and tissue analysis and waiver of consent was approved by University of Arizona Institutional Review Board.

\section{Consent for publication}

Not applicable.

\section{Competing interests}

The authors do not have conflict of interest.

\section{Author details}

'Department of Urology, The University of Arizona, 1501 N Campbell Ave, PO Box 245077, Tucson, AZ 85724-5077, USA. ²Department of Urology, University of California Los Angeles, 10833 Le Conte Avenue, Box 951738, Los Angeles, CA 90095-1738, USA. ${ }^{3}$ Department of Pathology and Immunology, Washington University in St. Louis, 660 S Euclid Ave, Campus, Box 8118, St. Louis, MO 63110, USA. ${ }^{4}$ Department of Surgery, University of Mississippi Medical Center, 2500 N State St, Jackson, MS 39216, USA. ${ }^{5}$ Department of Surgery, University of Arizona, 1501 N. Campbell Ave., Tucson, AZ 85724, USA. ${ }^{6}$ Department of Pathology, University of Arizona, 1501 N. Campbell Ave., Tucson, AZ 85724, USA.

Received: 28 February 2020 Accepted: 29 October 2020 Published online: 10 June 2021

\section{References}

1. Wein AJ, Kavoussi LR, Partin AW, Peters CA. Campbell-Walsh urology. Eleventh. Philadelphia: Elsevier; 2016.
2. Foster HE, Dahm P, Kohler TS, Lerner LB, Parsons JK, Wilt TJ, McVary KT. Surgical management of lower urinary tract symptoms attributed to benign prostatic hyperplasia: AUA Guideline Amendment 2019. J Urol. 2019;202(3):592-8.

3. Chughtai B, Forde JC, Thomas DD, Laor L, Hossack T, Woo HH, Te AE, Kaplan SA. Benign prostatic hyperplasia. Nat Rev Dis Primers. 2016;2:16031.

4. De Nunzio C, Presicce F, Tubaro A. Inflammatory mediators in the development and progression of benign prostatic hyperplasia. Nat Rev Urol. 2016;13:613.

5. Egan KB. The epidemiology of benign prostatic hyperplasia associated with lower urinary tract symptoms: prevalence and incident rates. Urol Clin N Am. 2016:43(3):259-97.

6. Platz EA, Kawachi I, Rimm EB, Willett WC, Giovannucci E. Race, ethnicity and benign prostatic hyperplasia in the Health Professinals Follow-up Study. J Urol. 2000;163(2):490-5.

7. Kristal Alan R, Arnold Kathryn B, Schenk Jeannette M, Neuhouser Marian L, Weiss N, Goodman P, Antvelink Colleen M, Penson David F, Thompson Ian M. Race/ethnicity, obesity, health related behaviors and the risk of symptomatic benign prostatic hyperplasia: results from the prostate cancer prevention trial. J Urol. 2007;177(4):1395-400.

8. Van Den Eeden SK, Shan J, Jacobsen SJ, Aaronsen D, Haque R, Quinn VP, Quesenberry CP Jr. Urologic diseases in America P: evaluating racial/ethnic disparities in lower urinary tract symptoms in men. J Urol. 2012;187(1):185-9.

9. Bhindi B, Margel D, Trottier G, Hamilton RJ, Kulkarni GS, Hersey KM, Finelli A, Trachtenberg J, Zlotta A, Toi A, et al. Obesity is associated with larger prostate volume but not with worse urinary symptoms: analysis of a large multiethnic cohort. Urology. 2014;83(1):81-7.

10. Fowke JH, Motley SS, Cookson MS, Concepcion R, Chang SS, Wills ML, Smith JA Jr. The association between body size, prostate volume and prostate-specific antigen. Prostate Cancer Prostatic Dis. 2006;10:137.

11. Kim JM, Song PH, Kim HT, Moon KH. Effect of obesity on prostatespecific antigen, prostate volume, and international prostate symptom score in patients with benign prostatic hyperplasia. Korean J Urol. 2011;52(6):401-5.

12. Wang $S$, Mao $Q$, Lin $Y$, Wu J, Wang $X$, Zheng $X$, Xie L. Body mass index and risk of BPH: a meta-analysis. Prostate Cancer Prostatic Dis. 2011;15:265-72.

13. Nandy PR, Saha S. Association between components of metabolic syndrome and prostatic enlargement: An Indian perspective. Med J Armed Forces India. 2016;72(4):350-5.

14. Chen Z, Miao L, Gao X, Wang G, Xu Y. Effect of obesity and hyperglycemia on benign prostatic hyperplasia in elderly patients with newly diagnosed type 2 diabetes. Int J Clin Exp Med. 2015;8(7):11289-94.

15. Gacci M, Sebastianelli A, Salvi M, De Nunzio C, Vignozzi L, Corona G, Jaeger T, Chini T, Russo Gl, Maggi M, et al. Benign prostatic enlargement can be influenced by metabolic profile: results of a multicenter prospective study. BMC Urol. 2017;17(1):22.

16. Meng J, Liu Y, Guan SY, Ma H, Zhang X, Fan S, Hu H, Zhang M, Liang C. Age, height, BMI and FBG predict prostate volume in ageing benign prostatic hyperplasia: Evidence from 5285 patients. Int J Clin Pract. 2019;2019:e13438.

17. Li BH, Deng T, Huang Q, Zi H, Weng H, Zeng XT. Body mass index and risk of prostate volume, international prostate symptom score, maximum urinary flow rate, and post-void residual in benign prostatic hyperplasia patients. Am J Mens Health. 2019;13(4):1557988319870382.

18. Hales CM, Carroll MD, Fryar CD, Ogden CL. Prevalence of obesity and severe obesity among adults: United States, 2017-2018. NCHS Data Brief. 2020;360:1-8.

19. Health, United Sates, 2018

20. Fowke JH, Koyama T, Fadare O, Clark PE. Does inflammation mediate the obesity and $\mathrm{BPH}$ relationship? an epidemiologic analysis of body composition and inflammatory markers in blood, urine, and prostate tissue, and the relationship with prostate enlargement and lower urinary tract symptoms. PLoS ONE. 2016;11(6):e0156918.

21. Luo J, Dunn T, Ewing C, Sauvageot J, Chen Y, Trent J, Isaacs W. Gene expression signature of benign prostatic hyperplasia revealed by cDNA microarray analysis. Prostate. 2002;51(3):189-200.

22. Nakanishi Y, Masuda H, Kawakami S, Sakura M, Fuji Y, Saito K, Koga F, Ito $\mathrm{M}$, Yonese J, Fukui I, et al. A novel equation and nomogram including 
body weight for estimating prostate volumes in men with biopsy-proven benign prostatic hyperplasia. Asian J Androl. 2012;14(5):703-7.

23. Telli O, Demirbas A, Kabar M, Karagoz MA, Sarici H, Resorlu B. Does metabolic syndrome or its components correlate With lower urinary tract symptoms in benign prostatic hyperplasia patients? Nephrourol Mon. 2015;7(3):e27253-e27253.

24. Egan KB, Burnett AL, McVary KT, Ni X, Suh M, Wong DG, Rosen RC. The co-occurring syndrome-coexisting erectile dysfunction and benign prostatic hyperplasia and their clinical correlates in aging men: results from the National Health and Nutrition Examination Survey. Urology. 2015;86(3):570-80.

25. Yee $\mathrm{CH}$, So WY, Yip SK, Wu E, Yau P, Ng CF. Effect of weight reduction on the severity of lower urinary tract symptoms in obese male patients with benign prostatic hyperplasia: a randomized controlled trial. Kor J UROL. 2015;56(3):240-6.

26. Flegal KM, Kruszon-Moran D, Carroll MD, Fryar CD, Ogden CL. Trends in obesity among adults in the united states, 2005 to 2014. JAMA. 2016;315(21):2284-91.

27. Story M, Evans M, Fabsitz RR, Clay TE, Rock BH, Broussard B. The epidemic of obesity in American Indian communities and the need for childhood obesity-prevention programs. Am J Clin Nutr. 1999;69(4):747S-754S.

28. Summary Health Statistics: National Health Interview Survey, 2014

29. Shih H-J, Huang C-J, Lin J-A, Kao M-C, Fan Y-C, Tsai P-S. Hyperlipidemia is associated with an increased risk of clinical benign prostatic hyperplasia. Prostate. 2018;78(2):113-20.

30. Petrus P, Mejhert N, Corrales P, Lecoutre S, Li Q, Maldonado E, Kulyté A, Lopez Y, Campbell M, Acosta JR, et al. Transforming growth factor- $\beta 3$ regulates adipocyte number in subcutaneous white adipose tissue. Cell Rep. 2018;25(3):551-560.e555.

31. Lin E, Kuo P-H, Liu Y-L, Yang AC, Tsai S-J. Transforming growth factor- $\beta$ signaling pathway-associated genes SMAD2 and TGFBR2 are implicated in metabolic syndrome in a Taiwanese population. Sci Rep. 2017:7(1):13589-13589.
32. Rugsarash $W$, Tungtrongchitr $R$, Petmitr S, Phonrat B, Pongpaew $P$, Harnroongroj T, Tungtrongchitr A. The genetic association between alpha-2-macroglobulin (A2M) gene deletion polymorphism and low serum A2M concentration in overweight/obese Thais. Nutr Neurosci. 2006;9(1-2):93-8.

33. Elam MB, Cowan GS Jr, Rooney RJ, Hiler ML, Yellaturu CR, Deng X, Howell GE, Park EA, Gerling IC, Patel D, et al. Hepatic gene expression in morbidly obese women: implications for disease susceptibility. Obesity (Silver Spring, Md). 2009;17(8):1563-73.

34. Fromont G, Chene L, Latil A, Bieche I, Vidaud M, Vallancien GUY, Mangin P, Fournier G, Validire P, Cussenot O. Molecular profiling of benign prostate hyperplasia using a large scale real-time reverse transcriptase-polymerase chain reaction approach. Urology. 2004;172(4, Part 1):1382-5.

35. Middleton LW, Shen Z, Varma S, Pollack AS, Gong X, Zhu S, Zhu C, Foley JW, Vennam S, Sweeney RT, et al. Genomic analysis of benign prostatic hyperplasia implicates cellular re-landscaping in disease pathogenesis. JCl insight. 2019;5(12):e129749.

36. Lucia MS, Lambert JR. Growth factors in benign prostatic hyperplasia: basic science implications. Curr Urol Rep. 2008;9(4):272-8.

37. Lloyd Granville L, Ricke William A, McVary Kevin T. Inflammation, voiding and benign prostatic hyperplasia progression. J Urol. 2019;201(5):868-70.

38. La Vignera S, Condorelli RA, Russo GI, Morgia G, Calogero AE. Endocrine control of benign prostatic hyperplasia. Andrology. 2016;4(3):404-11.

39. Liu D, Shoag JE, Poliak D, Goueli RS, Ravikumar V, Redmond D, Vosoughi A, Fontugne J, Pan H, Lee D, et al. Integrative multiplatform molecular profiling of benign prostatic hyperplasia identifies distinct subtypes. Nat Commun. 2020;11(1):1987.

\section{Publisher's Note}

Springer Nature remains neutral with regard to jurisdictional claims in published maps and institutional affiliations.
Ready to submit your research? Choose BMC and benefit from:

- fast, convenient online submission

- thorough peer review by experienced researchers in your field

- rapid publication on acceptance

- support for research data, including large and complex data types

- gold Open Access which fosters wider collaboration and increased citations

- maximum visibility for your research: over $100 \mathrm{M}$ website views per year

At BMC, research is always in progress.

Learn more biomedcentral.com/submissions 